\title{
A Placenta da Gestante Diabética
}

Tese de Doutorado. Curso de Pós-Graduação em Ginecologia e Obstetrícia, Área de Concentração em Obstetrícia. Departamento de Ginecologia e Obstetrícia da Faculdade de Medicina de Botucatu - UNESP. Apresentada em 03/09/98.

Autor: César Pereira Lima

Orientador: Profa. Dra. Marilza Vieira Cunha Rudge

Justificativa: A pesquisa da histopatologia placentária de diabéticas e de intolerantes a hidratos de carbono (HC), proteínas e lipídios (grupo IB de Rudge) é importante para entender as taxas de mortalidade perinatal.

Objetivo geral: Analisar a influência da classificação clínica de White e da classificação diagnóstica de Rudge sobre as alterações histopatológicas das placentas.

Material e métodos: Amostras de 131 placentas de gestantes, atendidas no Hospital das Clinicas de Botucatu (1991 a 1996): seis do grupo IA, 34 do grupo IB, oito do grupo IIA, que correspondem às diabéticas gestacionais da classe A (White) e 83 do grupo IIB, que correspondem às diabéticas, gestacionais e clínicas, das classes A à FRH. A qualidade do controle glicêmico foi analisada pela média glicêmica da gestação, com limite de 120 $\mathrm{mg} / \mathrm{dl}$. A idade da gestação foi individualizada em termo e pré-termo.
Conclusões: As 22 alterações histopatológicas de placentas de gestantes diabéticas foram semelhantes àquelas das não diabéticas e, independeram da classificação clínica de White. Essas alterações não se relacionaram com a idade gestacional ao nascimento e com a qualidade do controle glicêmico materno. As placentas das diabéticas do grupo IIB apresentaram os 22 tipos de alterações histopatológicas analisadas, sendo 21 no pré-termo. As placentas das diabéticas do grupo IIA apresentaram nove tipos de alterações com aumento significativo de dismaturidade, baixo indice de calcificação e ausência de nós sinciciais. As placentas das gestantes grupo IB apresentaram 17 tipos de alterações com aumento significativo de nós sinciciais e endarterite.

Palavras-chaves: Complicações da gravidez. Diabetes mellitus na gestação. Placenta, mortalidade perinatal.

\section{Monitorização Ambulatorial da Pressão Arterial (Mapa) em Pacientes com Doença Hipertensiva Especifica da Gestação. Correlação dos Achados com 0 Grau de Proteinúria}

Tese de Mestrado da Faculdade de Ciências Médicas da Universidade de Pernambuco, apresentada em 10/08/98.

Autor: Francisco Manoel C. de Mendonça

Orientador: Prof. Dr. Hélio de Lima Ferreira Fernandes Costa

O estudo teve como objetivos avaliar as características da pressão arterial nas 24 horas, em 32 gestantes com diagnóstico de doença hipertensiva específica da gestação, com proteinúria, utilizando a monitorização ambulatorial da pressão arterial (MAPA) nas 24 horas; avaliar a correlação dos niveis de proteinúria do grupo com os parâmetros observados durante a MAPA e avaliar a aceitação e possiveis complicações do método. O estudo foi do tipo descritivo com comparação de grupos. Na primeira etapa, foram descritos os parâmetros da MAPA onde observou-se que as médias da pressão arterial sistólica (PAS), pressão arterial diastólica (PAD) e 
pressão arterial média (PAM). estiveram mais elevadas no periodo da vigilia em relação ao do sono, o ritmo circadiano da PA apresentou descenso noturno em 31,3\% (PAS) e 56,3\% (PAD), atenuação em $62,5 \%$ (PAS) e 37,5\% (PAD), e inversão em 6,2\% (PAD). No período da vigília observou-se maior número de picos tensionais e maior variabilidade da PA em comparação com o período de sono. A variabilidade foi em média $12,9 \mathrm{mmHg}$ para a PAS e $11,3 \mathrm{mmHg}$ para a PAD no grupo estudado. Observou-se maior incidência de picos tensionais nos períodos entre 8 e 10 horas e entre 17 e 19 horas. Apresentaram carga pressórica anormal
(>30\%) 24 das nossas pacientes (75\%). Na comparação dos achados com o grau de proteinúria, observou-se correlação positiva com a média das PAS, PAD e PAM $(\mathrm{p}<0,05)$. Graus mais acentuados de proteinúria estiveram associados a quedas noturnas menos pronunciadas da PA da vigília para o sono, maior número de picos tensionais e carga pressórica na vigília $(\mathrm{r}=0,532 \mathrm{e}$ $\mathrm{p}<0,02)$ e sono $(\mathrm{r}=0,727$ e $\mathrm{p}<0,01)$. Por último observamos que a aceitação do método pelas pacientes foi total e as complicações mínimas.

Palavras-chave: Hipertensão arterial. Proteinúria. Pré-natal.

\section{Estudo Prospectivo, Comparativo da Isradipina e Atenolol no Tratamento de Gestantes Hipertensas}

Tese de Doutorado - Faculdade de Medicina, Universidade de São Paulo, apresentada em 11/08/98.

Autor: Eliane Aparecida Alves

Orientador: Prof. Dr. Soubhi Kahhale

O objetivo deste estudo foi o de avaliar a eficácia e a segurança de dois agentes antihipertensivos, a isradipina e o atenolol, no tratamento da hipertensão na gravidez. O estudo foi prospectivo, randômico e controlado. As pacientes foram divididas em dois grupos de 47 gestantes, para as quais foram ministrados isradipina na dose de $5 \mathrm{mg}$ duas vezes ao dia ou atenolol, $50 \mathrm{mg}$ duas vezes ao dia. Comparadas com os valores pré-tratamento, as pressões arteriais sistólicas e diastólicas sofreram redução estatisticamente significante nos dois grupos. O atenolol reduziu a freqüência cardiaca materna $(\mathrm{F}=8,17 ; \mathrm{p}<0,01)$. Na avaliação da vitalidade fetal em ambos os grupos, a dopplervelocimetria foi considerada normal em um número estatisticamente superior nas pacientes do grupo da isradipina $(p=0,03)$. Não foram observadas diferenças significantes ao serem avaliados o perfil biofísico dos fetos e o índice de líquido amniótico. A idade gestacional média na ocasião do parto foi 37,5 semanas no grupo da isradipina e 37,2 semanas no grupo do atenolol, sem diferença estatisticamente significativa entre eles. Os recémnascidos considerados pequenos para a idade gestacional foram $5(10,6 \%)$ no grupo da isradipina e $9(19,1 \%)$ do grupo atenolol, também sem diferença significante entre os dois $(p=0,76)$. Concluímos que ambas as drogas foram efetivas no tratamento da hipertensão arterial da gravidez, sem acarretar efeitos adversos considerados importantes.

Palavras-chave: Hipertensão arterial. Vitalidade fetal. Velocimetria. Líquido amniótico. 